\title{
PELATIHAN DAN PENDAMPINGAN TEKNOLOGI ASAP CAIR MENGGUNAKAN LIMBAH PERTANIAN DI KECAMATAN PARENGAN, TUBAN
}

\section{THE TRAINING AND MENTORING OF LIQUID SMOKE TECHNOLOGY USING AGRICULTURE WASTE IN PARENGAN DISTRICT, TUBAN}

\author{
${ }^{1)}$ Adi Rastono, ${ }^{2)}$ Refa Firgiyanto, ${ }^{3)}$ Pitri Ratna Asih, ${ }^{4}$ Ega Faustina, ${ }^{5)}$ Dita Megasari \\ ${ }^{1,2,3,4,5)}$ Program Studi Produksi Pangan dan Hortikultura, Politeknik Pertanian dan Peternakan Mapena \\ Tuban. \\ Jl. Raya Bojonegoro-Lasem Km 32, Laju Lor Singgahan, Tuban, Indonesia \\ email: risty.rasto@yahoo.co.id
}

\begin{abstract}
ABSTRAK
Pada era globalisasi persoalan mengenai pencemaran dan kerusakan lingkungan menjadi suatu permasalahan yang masih belum bisa dipecahkan oleh masyarakat secara berkelanjutan. Salah satu penyebabnya adalah penumpukan limbah seperti limbah pertanian. Tujuan kegiatan pengabdian ini adalah untuk mengolah limbah pertanian menjadi produk asap cair yang multifungsi dengan menggunakan metode pirolisis.Kegiatan pengabdian dilaksanakan mulai bulan Agustus sampai dengan Desember 2017 di Desa Sukorejo Kecamatan Parengan Kabupaten Tuban dengan kelompok sasaran adalah petani. Metode kegiatan ini meliputi a) penyuluhan dengan tujuan meningkatkan pemahaman petani dalam mengelola limbah pertanian menjadi asap cair, b) Difusi Iptek melalui pembuatan peralatan asap cair dengan menggunakan metode pirolisis, c) Pelatihan dan pendampingan dalam proses pembuatan asap cair berbahan limbah pertanian disertai dengan monitoring dan evaluasi. Hasil dari kegiatan adalah meningkatkan pengetahuan dan ketrampilan mitra, terciptanya instalansi alat pembuatan asap cair dan asap cair berbahan limbah pertanian yang multifungsi.
\end{abstract}

Kata Kunci: Asap cair, Limbah, Pelatihan, Pendampingan, Pestisida.

\begin{abstract}
In the era of globalization the issue of pollution and environmental damage becomes a problem that still can not be solved by society in a sustainable manner. One reason is the accumulation of waste such as agricultural waste. The purpose of this activity is to treat agricultural waste into a multifunctional liquid smoke product using pyrolysis method.The activity was carried out from August to December 2017 in Sukorejo Village, Parengan District, Tuban Regency with the target group is farmers. The methods of this activity include a) counseling with the aim of improving the understanding of farmers in managing agricultural waste into liquid smoke, b) Making liquid smoke equipment using pyrolysis method, c) Training and assistance in the process of making liquid smoke made from agricultural waste accompanied by monitoring and evaluation. The result of this activity is to improve the knowledge and skills of partners, the creation of liquid smoke making equipment by pyrolysis method and liquid smoke made from agricultural waste that is multifunctional in agricultural cultivation and publication using mass media.
\end{abstract}

Key Words: Liquid Smoke, Waste, Training, Assistance, Pesticides.

Submitted : 5 Januari 2018 Revision: 25 April 2018 Accepted: 4 Juli 2018 
Adi Rastono, Refa Firgiyanto, Pitri Ratna Asih, Ega Faustina, Dita Megasari

Pelatihan Dan Pendampingan Teknologi Asap Cair Menggunakan Limbah Pertanian Di

Kecamatan Parengan, Tuban

\section{PENDAHULUAN}

Limbah merupakan salah satu penyebab dari pencemaran dan kerusakan lingkungan. Menurut Rahmanto (2011), Limbah dapat diartikan sebagai segala sesuatu yang dihasilkan dari aktifitas manusia dan tidak memiliki nilai ekonomi. Berdasarkan sumber limbahnya, limbah pertanian merupakan salah satu jenis limbah yang masih terus menjadi permasalahan terutama didaerah pedesaan. Desa Sukorejo Kecamatan Parengan adalah salah satu Desa yang berada di Kabupaten Tuban dengan jumlah penduduk mencapai \pm 4000 jiwa. Mayoritas masyarakat desa Sukorejo bermata pencaharian sebagai petani dan peternak. Pada saat panen raya, para petani pada umumnya meninggalkan banyak limbah pertanian. Limbah tersebut berupa rontokan daun, patahan ranting, sekam, jerami sisa pakan ternak dan tongkol jagung. Pengelolaan limbah yang telah dilakukan pada umumnya masih belum optimal dan berkelanjutan dengan misalnya hanya ditinggalkan membusuk diarea pertanaman atau hanya dibakar di area persawahan yang memiliki dampat negatif bagi lingkungan. Pengelolaan yang belum optimal ini dikarenakan kurangnya informasi dan pengetahuan petani terkait dengan pengelolaan limbah pertanian menjadi produk yang fungsional yang didukung oleh kualitas SDM petani yang cenderung rendah yang menyebabkan tidak adanya inovasi teknologi yang dapat dilakukan. Oleh karena itu dibutuhkan adanya suatu kegiatan pelatihan dan pendampingan dalam menerapakan suatu teknologi yang dapat mengolah limbah pertanian tersebut menjadi produk-produk fungsional yang bermanfaat bagi petani pada khususnya dan masyarakat pada umumnya.

Salah satu penerapan teknologi tepat guna tersebut adalah dengan mengelola limbah hasil pertanian menjadi produk yang bermanfaat yaitu asap cair dengan menggunakan metode pirolisis. Asap cair merupakan cairan hasil kondensasi dari asap kayu yang mengalami penyimpanan dan penyaringan untuk memisahkan tar dan bahanbahan tertentu melalui cerobong pirolisis (Atmaja 2009). Selain kayu, asap cair juga dapat dihasilkan dari bahan lain seperti tempurung kelapa, sabut kelapa, merang padi, bambu dan sampah organik (Sutin 2008; Hardianto \& Yunianta 2012; Ariyani et al. 2015; Sari et al. 2015). Berdasarkan hasil analisis yang telah dilakukan oleh Pszczola (1995), terdapat lebih dari 400 senyawa yang terkandung didalam asap cair. Senyawa tersebut terdiri atas senyawa yang fungsional dan senyawa yang berbahaya seperti senyawa tar dan hidrokarbon polisiklis aromatik (PAH) oleh karena itu dibutuhkan adanya redistilasi agar senayawa berbahaya tersebut dapat dihilangkan (Atmaja 2009). Kandungan senyawa yang fungsional dari asap cair dapat dipergunakan untuk bahan baku pengawet, antioksidan, pestisida, memperbaiki kualitas tanah dan menetralisir asam tanah (Nurhayati 2000; Basri 2010; Hartati 2015; Jahidin 2015; Sari et al. 2015).

Tujuan dari kegiatan pengabdian ini adalah untuk mengolah limbah pertanian menjadi produk asap cair yang multifungsi dengan menggunakan metode pirolisis melalui pelatihan dan pendampingan yang berkelanjutan.

\section{METODE KEGIATAN}

Metode pelaksanaan dalam kegiatan ini terdiri tiga tahapan yaitu a) Penyuluhan, b) Difusi Iptek melalui pembuatan instalansi asap cair dengan menggunakan metode pirolisis, c) Pelatihan dan pendampingan dalam proses pembuatan asap cair berbahan limbah pertanian disertai dengan monitoring dan evaluasi. 
Adi Rastono, Refa Firgiyanto, Pitri Ratna Asih, Ega Faustina, Dita Megasari

Pelatihan Dan Pendampingan Teknologi Asap Cair Menggunakan Limbah Pertanian Di

Kecamatan Parengan, Tuban

\section{Tahapan Penyuluhan}

Tahapan penyuluhan diawali terlebih dahulu dengan analisis kebutuhan masyarakat. Tujuannya adalah mengetahui secara langsung segala permasalahan terkait pengelolaan limbah pertanian. Analisis kebutuhan dilakukan dengan pembuatan FGD (Focus group discussion) antara mitra dengan tim pengabdian. Hasil analisis kebutuhan ini digunakan sebagai dasar dalam menentukan topik awal dari kegiatan pengabdian yaitu pengelolaan limbah pertanian menjadi asap cair dengan mengunakan metode pirolisis. Kegiatan pengabdian kemudian dilanjutkan dengan tahapan penyuluhan. Tujuannya adalah sebagai transfer informasi terkait dengan pengelolaan limbah pertanian menjadi asap cair kepada mitra dan penjelasan terkait dengan sarana dan prasarana pendukung yang dibutuhkan dalam pembuatan asap cair. Metode pendekatan diseminasi meliputi pendekatan agroekosistem dengan melihat kesesuai kondisi dan potensi wilayah serta pendekatan pemberdayaan dengan tujuan menumbuhkan kemandirian masyarakat dalam memanfaatkan sumber daya setempat.

\section{Difusi Iptek melalui pembuatan instalansi asap cair dengan menggunakan metode pirolisis}

Tahapan ini meliputi pmbuatan instalasi asap berpedoman pada prinsip metode pirolisis yaitu peruraian dengan bantun panas tanpa adanya oksigen atau adanya oksigen dengan jumlah yang terbatas. Peralatan yang digunakan dalam pembuatan instalansi antara lain yaitu ruang pembakar, wadah arang, penampung tar atau asap cair, destilator, pipa besi, pemanas, pipa PVC, pompa air, tangki air, dan penyangga. Langkah-langkah kerja pembuatan asap mengacu pada penelitian Yunus (2011). Tahapan kemudian dilanjutkan dengan uji operasi. Instalasi pengolahan limbah pertanian menjadi asap cair yang telah dibuat perlu dilakukan adanya uji operasi terlebih dahulu, Tujuannya adalah untuk memastikan instalansi dapat bekerja dengan benar. Uji operasi dilakukan dengan menggunakan limbah jerami disekitar wilayah lahan pertanian.

\section{Pelatihan dan Pendampingan}

Tahapan pelatihan terdiri atas pelatihan soft skill dan pelatihan pembuatan asap cair dengan metode pirolisis. Tujuan dari kegiatan tersebut adalah memotivasi mitra dalam bekerja dan berpikir kreatif serta inovatif untuk mengelola limbah pertanian menjadi produk fungsional dan peningkatan pengetahuan serta ketrampilan mitra dalam membuat asap cair dengan metode pirolisis. Kegiatan pelatihan kemudian dilanjutkan dengan kegiatan pendampingan. Kegaitan pendampingan juga disertai dengan kegiatan monitoring dan evaluasi. Tujuannya adalah untuk mengetahui perkembangan program, kendala dan permasalahan yang dihadapai serta mencari solusi dari permasalahan tersebut agar kegiatan pengabdian dapat berjalan secara berkelanjutan sampai mitra benar-benar menjadi mandiri dalam proses produksi asap cair.

\section{HASIL DAN PEMBAHASAN}

Hasil dari beberapa tahapan pelaksanaan pelatihan dan pendampingan teknologi asap cair yang multifungsi berbahan limbah pertanian sebagai berikuti :

1. Meningkatnya pengetahuan dan ketrampilan dari mitra terkait dengn pengelolaan limbah pertanian menjadi asap cair.

Pada saat sebelum kegiatan pelatihan dimulai melalui kegiatan Focus Group Discussion antara tim pengabdian dan mitra yang diwakilkan oleh Ibu Wiwik Hartati selaku Kepala Desa, Bapak Eko Handoyo selaku

JPPM ISSN: 2549 - 8347 (Online)

ISSN: 2579 - 9126 (Print)

Vol. 2 No. 2 September 2018 
Adi Rastono, Refa Firgiyanto, Pitri Ratna Asih, Ega Faustina, Dita Megasari

Pelatihan Dan Pendampingan Teknologi Asap Cair Menggunakan Limbah Pertanian Di

Kecamatan Parengan, Tuban

perwakilan tokoh masyarakat dan beberapa petani diketahui bahwa pengetahuan mitra terkait dengan pengelolaan limbah masih sangat sedikit. Hal tersebut tercermin dari ditemukannya banyak sekali limbah pertanian seperti jerami padi, sekam padi dan tongkol jagung yang belum termanfaatkan secara optimal. Oleh karena itu kegiatan utama yang dilakukan adalah transfer informasi dan pengetahuan terkait dengan pengelolaan limbah salah satunya menjadi asap cair. Tujuan diskusi adalah untuk mencari penyelesaian dari permasalahan dan menggali potensi mitra serta turut mendukung keberhasilan kegiatan pengabdian (Ferdiani, et. al. 2018). Penyuluhan dilakukan pada tanggal 4 November 2017 dibalai Desa Sukorejo dengan dihadiri oleh lebih dari 50 peserta perwakilan dari perangkat Desa, kelompok tani dan civitas akademika Poltana Mapena. Penyuluhan kemudian dilanjutkan dengan diskusi dan pelatihan soft skill dengan tema "Berfikir Kreatif dan Inovatif dengan merubah limbah pertanian" (Gambar 1).

Tahap penyuluhan dilakukan untuk mentransfer informasi. Transfer informasi merupakan hal perdana yang perlu dilakukan untuk menambah pengetahuan mitra (Hendarmin, et. al. 2018). Banyak sekali penelitian yang mengungkapkan kegunaan asap cair sebagai kebutuhan pertanian dan kebutuhan lainnya seperti pengawet. Wiyanto dan Mirani (2009) menunjukan hasil bahwa asap cair memiliki zat penghambat makan bersifat antifeedant skunder yang mempu mengendalikan hama ulat krop kubis Crocidolomia pavonana. Anggraini dan Yuniningsih (2017), dalam penelitinnya mengungkapkan kegunaan fungsi asap cair sebagai bahan pengawet ikan segar selama 2 hari.

Berdasarkan hasil kegiatan menunjukkan adanya minat dan motivasi yang tinggi dari petani untuk dapat mengolah limbah pertanian menjadi produk asap cair yang dapat bermanfaat kembali bagi bidang pertanian yang tercermin dari keaktifan petani selama kegiatan. Hasil ini sejalan dengan hasil pemberdayaan masyarakat oleh Sulistiyani et. al. (2016) yang menyatakan bahwa pelaksanaan kegiatan pengabdian masyarakat berhubungan dengan permasalahan limbah tulang ikan yang dapat diolah menjadi Produk Hidroksiapatit (Hydroxyapatite/HA) yang bermanfaat dalam berbagai produk olahan makanan, penjernihan air, dan terapi kalsium organik yang berguna untuk kesehatan tulang.

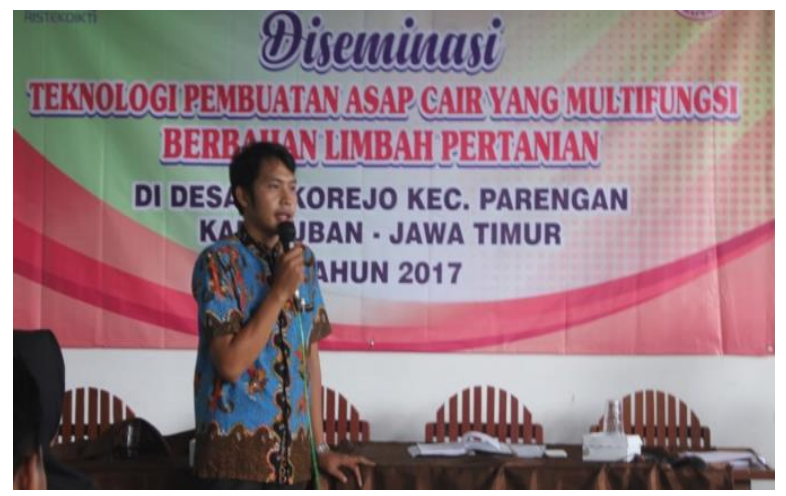

Gambar 1. Penyuluhan dan Pelatihan Soft Skill

2. Terciptanya instalansi alat pembuatan asap cair dan asap cair berbahan limbah pertanian yang multifungsi.

Pembuatan instalansi asap cair dilakukan selama dua bulan dengan jumlah jumlah total empat instalansi asap cair yang akan digunakan oleh empat kelompok tani di Desa Sukorejo Kecamatan Parengan (Gambar 2 dan 3). Adapun spesifikasi dan fungsi dari komponen dalam instalansi alat asap cair yang telah dibuat adalah sebagai berikut:

\section{a. Spesifikasi instalansi alat asap cair:}

Tungku Pembakaran : Terbuat dari plat besi dengan ketebalan $2 \mathrm{ml}$. 
Adi Rastono, Refa Firgiyanto, Pitri Ratna Asih, Ega Faustina, Dita Megasari

Pelatihan Dan Pendampingan Teknologi Asap Cair Menggunakan Limbah Pertanian Di Kecamatan Parengan, Tuban

Volume tungku pembakaran : P x L x T $=60 \mathrm{x}$ $60 \mathrm{x} 100 \mathrm{~cm}$

Ruang udara dalam tungku : Terbuat dari Besi galfanis ukuran 2 inchi

Ruang api pembakaran : Terbuat dari plat besi ukuran $20 \times 20 \times 25 \mathrm{~cm}$

Tutup kerucut : Terbuat dari plat besi dengan ukuran $60 \mathrm{~cm} \times 60 \mathrm{~cm}$

Pipa penghubug : Terbuat dari besi galfanis ukuran 2 inchi

Penampung asap :Terbuat dari stanles steel

Kondensator :Terbuat dari plat besi ketebalan 2ml, 40 x 40 x 50

Volume kondesator $\quad: \mathrm{P} \times \mathrm{L} \times \mathrm{T}=40 \times 40$ x $50 \mathrm{~cm}$

Pipa pegeluaran asap : Terbuat dari besi galfanis ketebalan 0,25 inchi

\section{Fungsi dari komponen dalam instalansi alat asap cair:}

Tungku pembakaran : Berfungsi sebagai ruang pembakaran bahan limbah pertanian

Kaki tungku

Berfungsi sebagai penyangga tungku dan sebagai ruang

tempat meletakan kompor gas

Penutup tungku kerucut : Berfungsi sebagai penutup agar asap tidak keluar dan menghubungkan asap menuju pipa panghubung kondensator

Pipa penghubung asap: Berfungsi mengalirkan asap menuju kondensator

Pipa rongga udara $\quad$ :Befungsi

mengalirkan udara supaya proses pembakaran tidak kedap dan merupakan jalannya udara untuk mendorong asap menuju pipa penghubung kondensator
Kondensator :Berfungsi sebagai pendingin asap dan merubah asap dari bentuk gas menjadi bentuk cair

Kompor gas :Berfungsi sebagai sumber perapian dalam pembakaran ruang pembakaran

Penampung air :Berfungsi sebagai sumber air untuk dimasukkan di dalam ruang kondestator

Pompa air :Berfungsi untuk sirkulasi air dari penampung air menuju ke kondensator

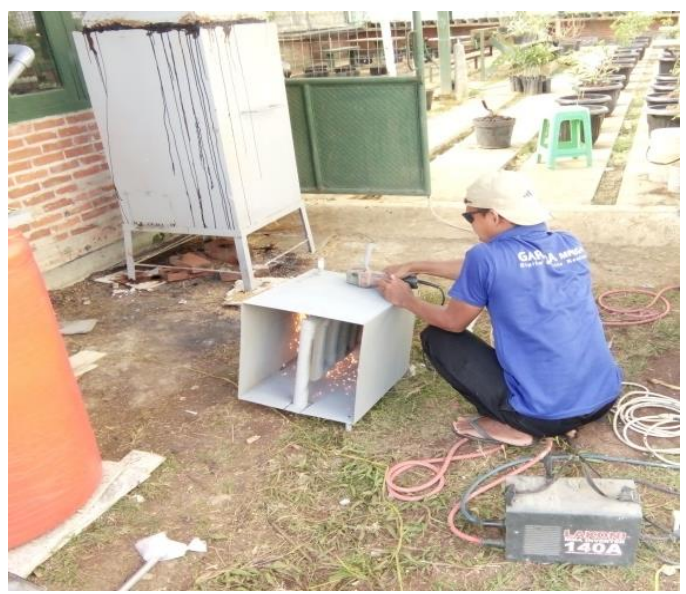

Gambar 2. Pembuatan instalansi asap cair

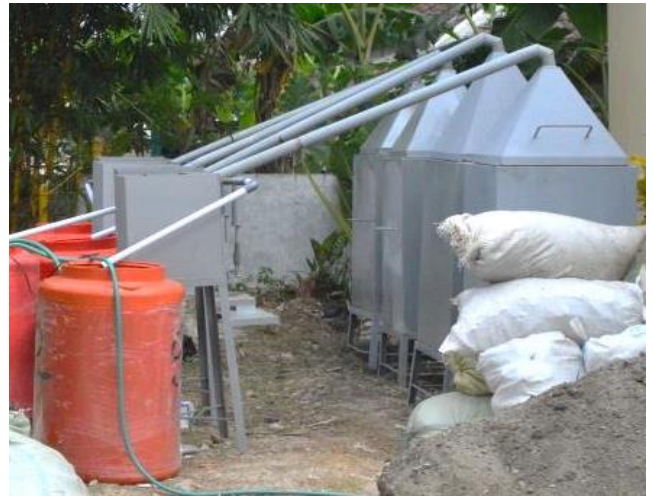

Gambar 3. Instalansi asap cair yang sudah jadi 
Adi Rastono, Refa Firgiyanto, Pitri Ratna Asih, Ega Faustina, Dita Megasari

Pelatihan Dan Pendampingan Teknologi Asap Cair Menggunakan Limbah Pertanian Di Kecamatan Parengan, Tuban

Adapaun prosedur kerja dari pembuatan asap cair menggunakan metode pirolisis Yunus (2011) adalah sebagai berikut:

1. Masukan limbah pertanian yang sudah dikeringkan ke dalam ruang pembakaran sampai penuh tapi tidak menutupi lubang atas ruang udara dalam tungku.

2. Tutup tungku dengan tabung kerucut yang akan terhubung dengan pipa yang akan menuju ke kondensator dengan dilapisi tanah agar tidak ada udara yang masuk atau keluar dari bagian tutup.

3. Nyalakan pemanas dibawah tabung tepat pada rongga pembakaran kuarang lebih 20-30 menit untuk membantu proses pembakaran, setelah itu matikan kompor gas. Asap yang keluar akan terdorong ke pipa galfanis yang menghubungkan tungku pembakaran (pirolisator) dengan kondensator.

4. Pengeluaran asap cair pertama pada pipa pengeluaran pertama sebelum masuk kondensator adalah bagian tar atau jelaga pengotor yang masih terkandung dalam asap cair.

5. Asap kemudian terus mengalir menuju ruang kondensator yang berisi air dingin, dalam kondensator terdapat tabung stainles penampung asap. Asap yang ditampung dalam tabung stainles akan mengembun dan menjadi cair.

6. Hasil pengembunan uap panas dari asap dari tangki kondensasi ini yang disebut dengan asap cair.

Kegiatan pelatihan praktek dan pendampingan pembuatan asap cair dilaksanakan berdasarkan prosedur SOP yang telah ada sebelumnya. Pendampigan sangat penting untuk dilakukan untuk menentukan keberhasilan program karena Masyarakat sebagai Pelaku pendamping sebagai fasilitator artinya pendamping perlu menempatkan masyarakat sebagai pelaku utama sedangkan pendamping bersifat membimbing (Maryani, et. al. 2018). Kegiatan praktek dan pendampingan di laksanakan di Kelompok tani Sri Mulyo Mandiri pada 9 dan 14 Desember 2017 yang dihadiri lebih dari sepuluh petani (Gambar 4).

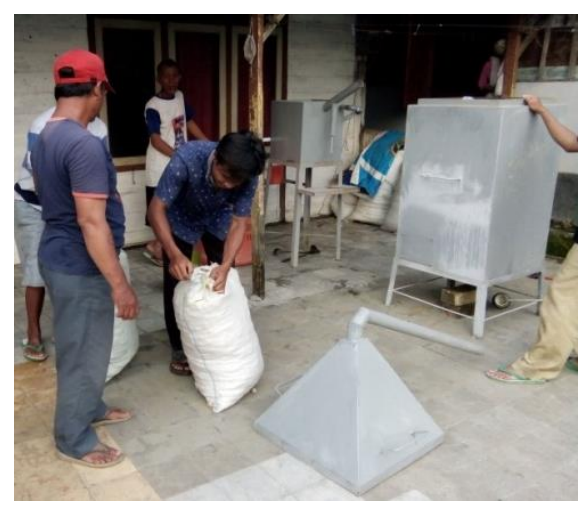

Gambar 4. Kegiatan Pendampingan operasional

Pada pelaksanaan pendampingan juga dilakukan kegiatan monitoring dan evaluasi agar program pengabdian berupa teknologi asap cair dapat berjalan secara berkelanjutan. Berdasarkan hasil monitoring dan evaluasi, masyarakat Desa Sukorejo sudah mulai memahami adanya pengolahan limbah pertanian menjadi asap cair. Hasil asap cair tersebut juga sudah digunakan oleh para petani untuk aplikasi pestisida dilahan pertanian sehingga dapat menghemat biaya masukkan selama proses budidaya pertanian. Kendala yang dihadapi sejauh ini masih belum ada karena mitra dapat bekerjasama dengan baik selama kegiatan pengabdian ini.

\section{SIMPULAN}


Adi Rastono, Refa Firgiyanto, Pitri Ratna Asih, Ega Faustina, Dita Megasari

Pelatihan Dan Pendampingan Teknologi Asap Cair Menggunakan Limbah Pertanian Di

Kecamatan Parengan, Tuban

Berdasarkan kegiatan pengabdian yang telah dilaksanakan, dapat disimpulkan bahwa semua rangkaian kegiatan telah berjalan dengan baik dan lancar dengan ditandai adanya motivasi yang tinggi dari mitra untuk dapat mengolah limbah pertanian menjadi produk yang lebih bermanfaat. Mitra juga sudah mengalami adanya peningkatan pengetahuan dan ketrampilan dalam mengelola limbah pertanian menjadi asap cair. Hasil asap cair sudah dapat digunakan oleh mitra sebagai input produksi dalam sistem budidaya pertanian misalnya digunakan sabagai pestisida nabati.

\section{DAFTAR PUSTAKA}

Ariyani D., Mujiyanti D.R., Umaningrum D., Halianto Y.A. (2015), studi kajian kandungan senyawa pada asap cair dari sekam padi. Prosiding. Seminar Nasional Kimia. J. Kimia FMIPA Universitas Negeri Surabaya 3-4 Oktober 2015.

Atmaja A. K. (2009). Aplikasi asap cair redestilasi pada karakterisasi kamaboko ikan tongkol (Euthynus affinis) ditinjau dari tingkat keawetan dan kesukaan konsumen. Skripsi. Fakultas Pertanian Universitas Sebelas Maret. Surakarta.

Basri AB. (2010). Manfaat asap cair untuk tanaman. Jurnal Serambi Pertanian. $4(5)$

Hardianto L., Yunianta. Pengaruh asap cair terhadap sifat kimia dan organoleptik ikan tongkoL (Euthynnus affinis). Jurnal Pangan \& Agroindustri. 3 (4): 1356-1366.
Hartati S., Darmadji P., Pranoto Y. 2015. Penggunaan asap cair tempurung kelapa untuk menurunkan kadar timbal $(\mathrm{Pb})$ pada biji kedelai (Glycine max). Agritech. 35 (3): 331339

Jahidin J. P. (2015). Pengaruh pengasapan sekam padi terhadap kualitas fisik dan kimia dendeng batokok. Jurnal Ilmu - Ilmu Peternakan. 18 (2): 8997.

Nurhayati T. (2000). Sifat destilat hasil destilasi kering 4 jenis kayu dan kemungkinan pemanfaatannya sebagai pestisida. Buletin Penelitian Hasil Hutan 17:160 - 168.

Pszczola D. E. (1995). Tour high light production and uses of smoke based flavors. Food Tech. 49 (1): 70-74.

Rahmanto M. I. (2011). Identifikasi Potensi dan Pemanfaatan Limbah Pertanian Di Kabupaten Bekasi. Jurnal Agribisnis. 2 (2).

Sari N. M., Mahdie M.F., Segah R. (2015). Rendemen arang sekam dan kualitas asap cair sekamPadi. Jurnal Hutan Tropis. 3 (3): 260-266.

Sutin. (2008). pembuatan asap cair dari tempurung dan sabut kelapa secara pirolisis serta fraksinasinya dengan ekstraksi. Skripsi. Fakultas Teknologi Pertanian Institut Pertanian Bogor. Bogor

Yunus, M. (2011). Teknologi Pembuatan Asap Cair Dari Tempurung Kelapa Sebagai Pengawet Makanan. Jurnal Sains \& Inovasi. 7(1): 53-61.

Ferdiani R.S., Murniasih T.R., Wilujeng S. Suwanti V. (2018). Penambahan Alat Produksi Guna Meningkatkan Roduktivitas Pengrajin Keset. Jurnal 
Adi Rastono, Refa Firgiyanto, Pitri Ratna Asih, Ega Faustina, Dita Megasari

Pelatihan Dan Pendampingan Teknologi Asap Cair Menggunakan Limbah Pertanian Di

Kecamatan Parengan, Tuban

Pengabdian Dan Pemberdayaan

Masyarakat 2 (1):23-28

Sulistiyani A.T., Aisyah D., Mamat I., Sontang M. (2016). Pemberdayaan Masyarakat Pemanfaatan Limbah Tulang Ikanuntuk Produk Hidroksiapatit (Hydroxyapatite/HA) Kajian di Pabrik Pengolahan Kerupuk Lekor Kuala TerengganuMalaysia. Indonesian Journal of Community Engagement , 02 (01)

Maryani I., Ahda M., Jatmika S.E.D. (2018). Efektivitas Pendampingan Kelompok Dalam Meningkatkan Motivasi Berwirausaha Peternak Sapi Perah. Jurnal Pengabdian dan Pemberdayaan Masyarakat. 2 (1) : 7-13

Hendarmin, Kartika M., Pebrianti W., (2018). Pelatihan Dan Pendampingan Pengolahan Komoditi Kelapa. Jurnal Pengabdian dan Pemberdayaan Masyarakat. 2 (1) : 1-6

Wiyantono dan Minarni E.W. (2009). Kajian Potensi Asap Cair Dalam Mengendalikan Ulat Krop Kubis Crocidolomia pavonana Jurnal Pembangunan Pedesaan. 9 (1): 5056

Anggraini S.P. A., dan Yuniningsih S. (2017). Optimalisasi Penggunaan Asap Cair Daritempurung Kelapa Sebagai Pengawet Alami Pada Ikan Segar. Jurnal Reka Buana. 2 (1): 11-18 